\title{
Comparative Evaluation of Seed and Grain Quality Parameters of Rice (Oryza sativa L.) Varieties under SRI and Conventional Methods of Rice Cultivation
}

\author{
G. Kumar ${ }^{*}$, L.V. Subba Rao ${ }^{2}$ and K. Keshavulu ${ }^{1}$ \\ ${ }^{1}$ Department of Seed Science and Technology, College of Agriculture, Professor Jayashankar \\ Telangana State Agricultural University, Hyderabad - 500030, Telangana, India \\ ${ }^{2}$ Crop Improvement Section, Directorate of Rice Research, Hyderabad - 500030, India \\ *Corresponding author
}

\section{A B S T R A C T}

Keywords

SRI (System of Rice Intensification),

Conventional

Transplanting (CT),

Varieties, Seed quality, Grain quality.

Article Info

Accepted:

27 June 2017

Available Online:

10 August 2017
Studies on comparative evaluation of seed and grain quality parameters of rice (Oryza sativa L.) varieties under SRI and conventional methods of rice cultivation was conducted at Directorate of Rice Research farm, ICRISAT campus, Patancheru, Hyderabad during Kharif 2013. Except seed germination all other seed quality parameters viz., seedling length, seedling dry weight, vigour index I and II (3005.82) (15430.22), respectively and grain quality parameters such as the grain length, amylose content and alkali spreading value recorded significantly higher values in SRI (System of Rice Intensification) method compared to Conventional Transplanting (CT). Akshayadhan recorded significantly higher seed quality parameters such as seedling length $(33.43 \mathrm{~cm})$, and vigour index II (19045.00). Hybrid PA 6444 recorded the higher seed vigour index I (3262.11). Amylose content recorded significantly higher values in Varadhan and alkali spreading value was significantly higher in Jaya. SRI method was found better over traditional method in respect of seed and grain quality attributes of rice.

\section{Introduction}

India is the largest producer of rice (Oryza sativa L.) next to China in the world. Rice cultivation is a huge water demanding enterprise. In recent years, water table has depleted at a very rapid rate throughout the globe, thus, posing alarming threats and limiting the scope for cultivation of high water consuming crops especially rice. Challenges in maintaining the sustainability of rice farming have been increasing with the increased scarcity of water and competition for water resources, declined yield levels with low grain quality and increasing the production costs due to more use of agriinputs (Chapagain and Yamaji, 2010). Therefore, it is very much important to search for water saving technologies without reducing the yields. System of Rice Intensification cultivation (SRI) is visualized as one of the water saving rice cultivation. SRI cultivation method offers to minimize water consumption for rice cultivation and to increase the productivity (Laulanie, 1993). System of rice intensification, developed in Madagascar in the 1980s, is a system approach to increase rice productivity with 
less external and inexpensive inputs. By adopting this system of cultivation we could save water, use organic matter, protect soil productivity, save environment, less input cost and increasing the production. And as conventional paddy cultivation was oldest method of rice cultivation. The conventional method needs extra labour and a lot of fertilizers. Good quality and healthy seed is a basic and critical input for the sustained agriculture production. Successful agriculture depends on the quality of seeds used for sowing. The establishment of the seedling depends upon the vigour of the seed, demanding each and every seed readily germinate and produce vigourous seedlings. Traditionally, plant breeders concentrated on breeding for high yields and pest resistance. Recently the trend has changed to incorporate preferred quality characteristics that increase the total economic value of rice. Grain quality is not just dependent on the variety of rice, but quality also depends on the crop production. Grain shape and L/B ratio are important features for grain quality assessment (Rita and Sarawgi, 2008). In this context, need to identify the suitable cultivars which respond well for SRI or conventional method. Keeping the above views in mind, a study was undertaken to comparative evaluation of seed and grain quality parameters of rice (Oryza sativa L.) varieties under SRI and conventional methods of rice cultivation.

\section{Materials and Methods}

The study was carried out at Directorate of Rice Research farm, ICRISAT campus, Patancheru, Hyderabad during kharif 2013, while laboratory studies were carried out at Directorate of Rice Research, Rajendranagar, Hyderabad. The field experiment was laid out in split - plot design with three replications with two methods of cultivation, System of Rice Intensification (SRI) and Conventional transplanting (CT) as main treatments and fifteen rice varieties of different groups as sub treatments viz., Tulasi, Ravi, Varadhan (early duration), Triguna, Jaya, Akshayadhan (medium duration), Swarnadhan, Phalguna, Dhanrasi (late duration), DRRH 3, PA 6444, US 382 (hybrids), Kasturi, Sugandhamathi and Vasumahti (scented). Seedlings of twelve days old were transplanted in the main field in square pattern, spacing at $25 \mathrm{~cm} \times 25 \mathrm{~cm}$ with single seedlings per hill in SRI method. Twenty five days old seedlings were transplanted in to main field at a spacing of 20 $\mathrm{cm} \times 15 \mathrm{~cm}$. At each hill, two to three seedlings were transplanted in conventional transplanting (CT).

Observations on seed and grain quality parameters of rice were recorded as per standard procedures. Seed quality parameters were studied; the seeds obtained from all the treatments were tested for laboratory germination (between-paper method) as per the procedures of ISTA (Anon, 1996). After final germination count, ten normal seedlings were selected at random in each replication for recording seedling length in centimeters and same seedlings were oven dried at $85^{0} \pm$ $1{ }^{0} \mathrm{C}$ for 24 hours and weighed $(\mathrm{mg})$ for seedling dry weight. Seed vigour index I and seed vigour index II were calculated by multiplying germination percent with seedling length and seedling dry weight, respectively (Abdul - Baki and Anderson, 1973). Grain quality parameters were also studied. Ten randomly selected rice grains were measured by using dial micrometer for grain length and breadth. Average of length and breadth was taken in millimeters and $\mathrm{L} / \mathrm{B}$ ratio was calculated. Based on length and L/B ratio following Ramaiah (1964) classification grain type was assigned as long slender (LS), short slender (SS), medium slender (MS), long bold (LB) and short bold (SB). For estimation of amylase content $100 \mathrm{mg}$ of rice flour was mixed with $1 \mathrm{ml}$ of $95 \%$ ethanol and $9 \mathrm{ml}$ of 
1.0N NaOH. This was mixed well and heated in a boiling water bath for 10 min. samples were diluted to $100 \mathrm{ml}$ with distilled water. From this suspension, $5 \mathrm{ml}$ of sample was taken and $1 \mathrm{ml}$ of acetic acid $(57.75 \mathrm{ml}$ in one litre water) was added to acidify the sample along with $1.5 \mathrm{ml}$ of iodine solution $(0.2 \%$ iodine $+2 \%$ potassium iodide) and the volume was made to $100 \mathrm{ml}$ with distilled water. The samples were incubated at room temperature for 20 minutes. The absorbance was measured at $620 \mathrm{~nm}$ using spectrophotometer. As a control, $\mathrm{NaOH}$ solution was used. The amylose content of different varieties was calculated in comparison with standard graph (Perez and Juliano, 1978).

Six whole polished rice grains were taken in petriplates and $10 \mathrm{ml}$ of $1.7 \%$ of $\mathrm{KOH}$ was added and kept in incubator at $27-30^{\circ} \mathrm{C}$ for 23 hours. The alkali spreading of kernels were noted on a seven point scale and calculated as low, low-intermediate, intermediate or high (Little et al., 1958). The experimental data recorded on various parameters were analyzed statistically following the analysis of variance procedure described by Gomez and Gomez (1984). Critical difference for examining treatmental means for their significance was calculated at $5 \%$ level of probability.

\section{Results and Discussion}

\section{Seed quality parameters}

Data pertaining to seed quality parameters were presented in table 1 . In both the methods of cultivation, final count of germination exhibited no significant difference. Significant differences were observed among all the varieties. Variety US 382 recorded the higher final count of germination $(98.67 \%)$, which was on par with PA 6444, DRRH 3 and Varadhan. The lowest final count of germination was recorded by variety Kasturi
(89.83\%). Interaction effect between methods of cultivation and varieties were found to be non - significant in the final count of germination per cent. These results are in conformity with the findings of Nandisha and Mahadevappa (1984) and Singh et al., (2013) who reported that higher germination was recorded in SRI method of cultivation.

In both the methods of cultivation, seedling length was significantly higher in SRI (31.40 $\mathrm{cm})$ compared to CT $(28.55 \mathrm{~cm})$. Significant differences were also observed among all the varieties. Variety Akshayadhan recorded the highest seedling length $(33.43 \mathrm{~cm})$, which was on par with PA $6444(37.17 \mathrm{~cm})$, US 382 $(32.80 \mathrm{~cm})$ and DRRH $3(33.17 \mathrm{~cm})$. The lowest seedling length was recorded by variety Sugandhamathi (26.42 cm). Interaction effect between methods of cultivation and varieties were found to be non - significant. In the present investigation, the seedling length was higher in SRI compare to conventional transplanting. These results are in conformity with the findings of Kanaka Durga (2012).

In both the methods of cultivation, seedlings dry weight was significantly higher in SRI (161.11 mg) compared to CT (154.89 mg). Significant differences were also observed among all the varieties. Variety Akshayadhan recorded the highest seedlings dry weight (196.67 mg), which was significantly superior to all other varieties and was followed by PA 6444, US 382, DRRH 3, Varadhan, Ravi, Jaya, Phalguna, Swarnadhan, Triguna, Vasumathi, Kasturi, Dhanrasi and Tulasi. The lowest seedlings dry weight was recorded by variety Sugandhamathi (138.33 mg). Interaction effect between methods of cultivation and varieties were found to be non - significant. Seedling dry weight higher in SRI compared to CT. Similar results were also reported by Kanaka Durga (2012). 
Table.1 Influence of SRI and conventional transplanting methods on germination (\%), seedling length (cm), seedling dry weight (mg), seed vigour index I and seed vigour index II in rice varieties

\begin{tabular}{|c|c|c|c|c|c|c|c|c|c|c|c|c|c|c|c|}
\hline \multirow{2}{*}{ Variety } & \multicolumn{3}{|c|}{ Germination (\%) } & \multicolumn{3}{|c|}{ Seedling length(cm) } & \multicolumn{3}{|c|}{ Seedling dry weight (mg) } & \multicolumn{3}{|c|}{ Vigour index I } & \multicolumn{3}{|c|}{ Vigour index II } \\
\hline & SRI & CT & Mean & SRI & CT & Mean & SRI & CT & Mean & SRI & CT & Mean & SRI & CT & Mean \\
\hline Tulasi & 93.67 & 90.67 & 92.17 & 30.42 & 27.30 & 28.86 & 150.00 & 140.00 & 145.00 & 2848.90 & 2474.48 & 2661.69 & 14050.00 & 12686.67 & 13368.33 \\
\hline Ravi & 95.33 & 94.33 & 94.83 & 32.04 & 28.59 & 30.31 & 160.00 & 156.67 & 158.33 & 3053.17 & 2696.64 & 2874.91 & 15253.33 & 14776.67 & 15015.00 \\
\hline Varadhan & 98.00 & 97.00 & 97.50 & 32.89 & 30.21 & 31.55 & 166.67 & 160.00 & 163.33 & 3224.27 & 2930.33 & 3077.30 & 16333.33 & 15520.00 & 15926.67 \\
\hline Triguna & 94.67 & 93.67 & 94.17 & 29.40 & 27.13 & 28.26 & 150.00 & 150.00 & 150.00 & 2782.53 & 2541.98 & 2662.26 & 14206.67 & 14043.33 & 14125.00 \\
\hline Jaya & 96.00 & 95.33 & 95.67 & 30.77 & 28.43 & 29.60 & 156.67 & 153.33 & 155.00 & 2953.50 & 2710.25 & 2831.87 & 15043.33 & 14613.33 & 14828.33 \\
\hline Swarnadhan & 95.00 & 92.67 & 93.83 & 30.37 & 27.53 & 28.95 & 153.33 & 150.00 & 151.67 & 2886.04 & 2550.82 & 2718.43 & 14570.00 & 13900.00 & 14235.00 \\
\hline Phalguna & 95.67 & 94.00 & 94.83 & 30.72 & 27.60 & 29.16 & 153.33 & 150.00 & 151.67 & 2938.61 & 2595.04 & 2766.83 & 14670.00 & 14110.00 & 14390.00 \\
\hline Dhanrasi & 97.33 & 95.67 & 96.50 & 29.62 & 27.20 & 28.41 & 146.67 & 143.33 & 145.00 & 2882.87 & 2601.17 & 2742.02 & 14273.33 & 13706.67 & 13990.00 \\
\hline DRRH 3 & 98.33 & 97.67 & 98.00 & 34.11 & 30.57 & 32.34 & 170.00 & 163.33 & 166.67 & 3354.39 & 2984.95 & 3169.67 & 16716.67 & 15946.67 & 16331.67 \\
\hline PA 6444 & 98.67 & 98.00 & 98.33 & 34.53 & 31.81 & 33.17 & 183.33 & 170.00 & 176.67 & 3406.67 & 3117.54 & 3262.11 & 18086.67 & 16660.00 & 17373.33 \\
\hline US 382 & 99.00 & 98.33 & 98.67 & 34.41 & 31.19 & 32.80 & 186.67 & 166.67 & 176.67 & 3406.59 & 3067.13 & 3236.86 & 18480.00 & 16386.67 & 17433.33 \\
\hline Kasturi & 90.33 & 89.33 & 89.83 & 29.48 & 27.08 & 28.28 & 146.67 & 146.67 & 146.67 & 2661.38 & 2419.20 & 2540.29 & 13246.67 & 13103.33 & 13175.00 \\
\hline Vasumathi & 92.67 & 91.67 & 92.17 & 29.30 & 26.92 & 28.11 & 150.00 & 146.67 & 148.33 & 2714.67 & 2467.47 & 2591.07 & 13900.00 & 13440.00 & 13670.00 \\
\hline Mean & 95.58 & 94.33 & 94.96 & 31.40 & 28.55 & 29.97 & 161.11 & 154.89 & 158.00 & 3005.82 & 2698.06 & 2851.94 & 15430.22 & 14636.44 & 15033.30 \\
\hline $\begin{array}{l}\text { For comparing } \\
\text { means of }\end{array}$ & \multicolumn{2}{|c|}{ SEm \pm} & CD at $5 \%$ & \multicolumn{2}{|c|}{ SEm \pm} & CD at $5 \%$ & SEm \pm & \multicolumn{2}{|c|}{ CD at $5 \%$} & \multicolumn{2}{|c|}{ SEm \pm} & CD at $5 \%$ & \multicolumn{2}{|c|}{ SEm \pm} & CD at $5 \%$ \\
\hline Methods (M) & \multicolumn{2}{|c|}{0.37} & NS & \multicolumn{2}{|c|}{0.07} & 0.46 & 0.31 & \multicolumn{2}{|c|}{1.94} & \multicolumn{2}{|c|}{6.64} & 40.93 & \multicolumn{2}{|c|}{46.14} & 284.67 \\
\hline Varieties (V) & \multicolumn{2}{|c|}{0.55} & 1.56 & \multicolumn{2}{|c|}{0.39} & 1.10 & 2.97 & \multicolumn{2}{|c|}{8.42} & \multicolumn{2}{|c|}{37.38} & 105.93 & \multicolumn{2}{|c|}{291.16} & 825.04 \\
\hline $\mathrm{M} \times \mathrm{V}$ & \multicolumn{2}{|c|}{0.84} & NS & \multicolumn{2}{|c|}{0.54} & NS & 4.07 & \multicolumn{2}{|c|}{ NS } & 51.5 & & $\mathrm{NS}$ & 400.47 & & NS \\
\hline $\mathrm{V} \times \mathrm{M}$ & 1.44 & & NS & 0.2 & & NS & 1.22 & & NS & 25.7 & & NS & 178.71 & & NS \\
\hline
\end{tabular}

SRI - System of Rice Intensification; CT- Conventional transplanting 
Table.2 Influence of SRI and conventional transplanting methods on grain length, grain breadth, L/B ratio, grain type, amylose content and alkali spreading value in rice varieties

\begin{tabular}{|c|c|c|c|c|c|c|c|c|c|c|c|c|c|c|c|c|}
\hline \multirow[b]{2}{*}{ Variety } & \multicolumn{3}{|c|}{ Grain length(mm) } & \multicolumn{3}{|c|}{ Grain breadth(mm) } & \multicolumn{3}{|c|}{ L/B ratio } & \multirow{2}{*}{$\begin{array}{c}\text { Grain } \\
\text { type }\end{array}$} & \multicolumn{3}{|c|}{ Amylose content (\%) } & \multicolumn{3}{|c|}{ Alkali spreading value } \\
\hline & SRI & CT & $\begin{array}{c}\text { Mea } \\
\mathbf{n}\end{array}$ & SRI & CT & Mean & SRI & CT & Mean & & SRI & CT & Mean & SRI & CT & Mean \\
\hline Tulasi & 9.00 & 8.71 & 8.85 & 2.05 & 1.99 & 2.02 & 4.39 & 4.38 & 4.39 & $\mathrm{LS}$ & 26.78 & 25.33 & 26.06 & 6.73 & 6.50 & 6.62 \\
\hline Ravi & 5.64 & 5.57 & 5.61 & 2.10 & 2.08 & 2.09 & 2.78 & 2.75 & 2.77 & MS & 27.82 & 25.86 & 26.84 & 4.60 & 4.23 & 4.42 \\
\hline Varadhan & 5.93 & 5.47 & 5.70 & 2.43 & 2.28 & 2.36 & 2.44 & 2.42 & 2.43 & SB & 27.16 & 26.63 & 26.90 & 4.50 & 4.20 & 4.35 \\
\hline Triguna & 9.38 & 9.03 & 9.20 & 1.88 & 1.82 & 1.85 & 5.02 & 4.99 & 5.00 & $\mathrm{LS}$ & 26.90 & 25.91 & 26.41 & 5.03 & 4.80 & 4.92 \\
\hline Jaya & 8.62 & 8.52 & 8.57 & 2.91 & 2.88 & 2.90 & 2.97 & 2.95 & 2.96 & LB & 26.65 & 25.79 & 26.22 & 7.00 & 6.67 & 6.83 \\
\hline $\begin{array}{l}\text { Akshayadha } \\
\mathrm{n}\end{array}$ & 8.65 & 8.44 & 8.54 & 2.90 & 2.86 & 2.88 & 2.98 & 2.95 & 2.96 & LB & 25.56 & 25.12 & 25.34 & 5.67 & 4.67 & 5.17 \\
\hline Swarnadhan & 5.90 & 5.62 & 5.76 & 2.56 & 2.51 & 2.54 & 2.38 & 2.25 & 2.31 & SB & 26.46 & 25.42 & 25.94 & 4.37 & 4.03 & 4.20 \\
\hline Phalguna & 9.63 & 9.40 & 9.52 & 1.88 & 1.85 & 1.86 & 5.14 & 5.10 & 5.12 & LS & 26.12 & 25.30 & 25.71 & 6.70 & 6.45 & 6.58 \\
\hline Dhanrasi & 5.57 & 5.41 & 5.49 & 2.33 & 2.32 & 2.32 & 2.46 & 2.44 & 2.45 & SB & 26.16 & 25.38 & 25.77 & 4.10 & 4.00 & 4.05 \\
\hline DRRH 3 & 5.87 & 5.63 & 5.75 & 2.20 & 2.15 & 2.18 & 2.69 & 2.65 & 2.67 & MS & 25.53 & 25.25 & 25.39 & 4.07 & 3.78 & 3.92 \\
\hline PA 6444 & 5.83 & 5.50 & 5.67 & 2.02 & 1.99 & 2.01 & 2.91 & 2.89 & 2.90 & MS & 25.94 & 25.86 & 25.90 & 5.33 & 4.83 & 5.08 \\
\hline US 382 & 5.85 & 5.61 & 5.73 & 2.11 & 2.05 & 2.08 & 2.84 & 2.80 & 2.82 & MS & 25.58 & 25.29 & 25.43 & 4.22 & 3.94 & 4.08 \\
\hline Kasturi & 10.18 & 9.59 & 9.88 & 1.71 & 1.65 & 1.68 & 5.97 & 5.81 & 5.89 & LS & 19.50 & 19.00 & 19.25 & 3.67 & 3.00 & 3.33 \\
\hline $\begin{array}{l}\text { Sugandhama } \\
\text { thi }\end{array}$ & 10.34 & 10.02 & 10.18 & 1.76 & 1.73 & 1.75 & 5.91 & 5.79 & 5.85 & LS & 25.56 & 25.10 & 25.33 & 6.83 & 6.48 & 6.66 \\
\hline Vasumathi & 10.22 & 9.56 & 9.89 & 1.74 & 1.65 & 1.70 & 5.89 & 5.80 & 5.85 & $\mathrm{LS}$ & 25.67 & 25.14 & 25.40 & 4.20 & 3.97 & 4.08 \\
\hline Mean & 7.77 & 7.47 & 7.62 & 2.17 & 2.12 & 2.15 & 3.78 & 3.73 & 3.76 & - & 25.83 & 25.09 & 25.46 & 5.13 & 4.77 & 4.95 \\
\hline $\begin{array}{l}\text { For } \\
\text { comparing } \\
\text { means of }\end{array}$ & SEm \pm & \multicolumn{2}{|c|}{ CD at $5 \%$} & SEm \pm & \multicolumn{2}{|c|}{ CD at $5 \%$} & SEm \pm & \multicolumn{2}{|c|}{ CD at $5 \%$} & - & \multicolumn{2}{|c|}{ SEm \pm} & $\begin{array}{c}\text { CD at } \\
5 \%\end{array}$ & SEm \pm & \multicolumn{2}{|c|}{ CD at $5 \%$} \\
\hline Methods (M) & 0.02 & \multicolumn{2}{|c|}{0.13} & \multicolumn{2}{|l|}{0.02} & NS & 0.04 & \multicolumn{2}{|c|}{$\mathrm{NS}$} & - & \multicolumn{2}{|c|}{0.12} & 0.72 & 0.04 & \multicolumn{2}{|c|}{0.23} \\
\hline Varieties (V) & 0.09 & \multicolumn{2}{|c|}{0.27} & \multicolumn{2}{|l|}{0.11} & 0.30 & 0.16 & \multicolumn{2}{|c|}{0.45} & - & \multicolumn{2}{|c|}{0.60} & 1.69 & 0.23 & \multicolumn{2}{|c|}{0.67} \\
\hline $\mathrm{M} \times \mathrm{V}$ & 0.13 & \multicolumn{2}{|c|}{$\mathrm{NS}$} & \multicolumn{2}{|l|}{0.15} & NS & 0.22 & & $\mathrm{NS}$ & - & 0.8 & & NS & 0.32 & & $\mathrm{IS}$ \\
\hline $\mathrm{V} \times \mathrm{M}$ & 0.08 & & NS & 0.07 & & NS & 0.16 & & NS & - & 0.4 & & NS & 0.14 & & $\mathrm{IS}$ \\
\hline
\end{tabular}

SRI - System of Rice Intensification; CT- Conventional transplanting 
In both the methods of cultivation, seed vigour index I was significantly higher in SRI (3005.82) compare to CT (2698.06). Significant differences were also observed among all the varieties. Variety PA 6444 recorded the higher seed vigour index I (3262.11), which was on par with Akshayadhan, US 382 and DRRH 3. The lowest seed vigour index I was recorded by variety Sugandhamathi (2404.38). Interaction effect between methods of cultivation and varieties were found to be non - significant. The SRI method produced seeds have better quality than CT. The better filling of seeds and higher test weight, which indicates the better food reserves in the seeds produced with these methods, might have resulted in better quality parameter. These results are in agreement with the observations of Nandisha and Mahadevappa (1984) and Kanaka Durga (2012).

In both the methods of cultivation, seed vigour index II was significantly higher in SRI (15430.22) compare to CT (14636.44). Significant differences were also observed among all the varieties. Variety Akshayadhan recorded the higher seed vigour index II (19045.00), which was significantly superior to all other varieties and was followed by US 382 (17433.33), PA 6444 (17373.33), DRRH 3 (16331.67), Varadhan (15926.67), Ravi (15015), Jaya (14828.33), Phalguna (14390), Swarnadhan (14235), Triguna (14125), Dhanrasi (13990), Vasumathi (13670), Tulasi (13368.33), and Kasturi (13175). The lowest seedling vigour index II was recorded by variety Sugandhamathi (12593.33). Interaction effect between methods of cultivation and varieties were found to be non - significant. The vigour index was significantly higher with SRI. The better seed quality produced under SRI may be due to higher test weight values. These results are in conformity with the findings of Nandisha and Mahadevappa (1984), Udaykumar (2005) and Singh et al., (2013).

\section{Grain quality parameters}

Data pertaining to grain quality parameters were presented in table 2 . In both the methods of cultivation, grain length was significantly higher in SRI (7.77 mm) compare to CT (7.47 $\mathrm{mm})$. Significant differences were also observed among all the varieties. Variety Sugandhamathi recorded higher grain length $(10.18 \mathrm{~mm})$, which was significantly superior over all other varieties and was followed by Vasumathi, Kasturi, Phalguna, Triguna, Tulasi, Jaya, Akshayadhan, Swarnadhan, DRRH 3, US 382, Varadhan, PA 6444 and Ravi. The lowest grain length was recorded by variety Dhanrasi $(5.49 \mathrm{~mm})$. Interaction effect between methods of cultivation and varieties were found to be non - significant for grain length. In both the methods of cultivation, grain breadth had shown non significant difference. Significant differences were observed among all the varieties. Variety Jaya recorded the higher grain breadth $(2.90 \mathrm{~mm})$, which was on par with Akshayadhan. The lowest grain breadth was recorded by variety Kasturi $(1.68 \mathrm{~mm})$. Interaction effect between methods of cultivation and varieties were found to be non - significant for grain breadth. There is no significance difference between the methods of cultivation for L/B ratio. Significant differences were observed among all the varieties. Variety Kasturi recorded the higher L/B ratio (5.89), which was on par with Sugandhamathi and Vasumathi. The lowest L/B ratio was recorded by variety Swarnadhan (2.31). Interaction effect between methods of cultivation and varieties were found to be non - significant for $\mathrm{L} / \mathrm{B}$ ratio. Based on the $\mathrm{L} / \mathrm{B}$ ratio, the collected rice varieties were classified into different categories such as Tulasi (long slender), Ravi (medium slender), Varadhan (short bold), Triguna (long slender), Jaya (long bold), Akshayadhan (long bold), Swarnadhan (short bold), Phalguna (long slender), Dhanrasi 
(short bold), DRRH 3 (medium slender), PA 6444 (medium slender), US 382 (medium slender), Kasturi (long slender), Sugandhamathi (long slender) and Vasumathi (long slender). The grain length, bredth and L/B ratio higher in SRI compare to $\mathrm{CT}$ due to better grain filling in SRI. These results are in conformity with the findings of Bhonsle and Krishnan (2010).

In both the methods of cultivation, amylose content was significantly higher in SRI (25.83\%) compare to CT $(25.09 \%)$ because of reduction of irrigation water and longer period of grain filling. Significant differences were also observed among all the varieties. The variety Varadhan recorded the highest amylose content $(26.90 \%)$, which was on par with Ravi, Triguna, Jaya, Tulasi, Swarnadhan, PA 6444, Dhanrasi, Phalguna, US 382, Vasumathi, DRRH 3, Akshayadhan and Sugandhamathi. The lowest amylose content was recorded by variety Kasturi (19.25\%). Interaction effect between methods of cultivation and varieties were found to be non - significant in the amylose content. The amylose content may be classified on milled rice basis as waxy $(1-2 \%)$ or non-waxy $(>$ $2 \%)$, very low $(2-10 \%)$, low $(10-20 \%)$, intermediate $(20-25 \%)$ and high $((>25 \%)$. Among the varieties studied, Amylose content ranged from 19.25 - $26.90 \%$ and grouped under near low and intermediate to high. These results are in agreement with the observations of (Shukla et al., 2016).

In both the methods of cultivation, alkali spreading value was significantly higher in SRI (5.13) compare to CT (4.77). Significant differences were also observed among all the varieties. Variety Jaya recorded the highest alkali spreading value (6.83), which was on par with Sugandhamathi, Tulasi and Phalguna. The lowest alkali spreading value was recorded by variety Kasturi (3.33). Interaction effect between methods of cultivation and varieties were found to be non - significant in the alkali spreading value. Alkali spreading value has been used to indicate the gelatinization temperature. The alkali value is negatively associated with gelatinization temperature. Gelatinization temperature can be rated based on the alkali spreading value as high (1 - 2\%), high intermediate (3), intermediate (4 - 5) and low $(6-7)$. In general, all the varieties under study had their alkali values within the range of 3.33 to 6.83.This moderate to high damage of rice kernal in alkali solution indicated intermediate to low gelatinization temperature. Such rice types will take lower temperature and lesser time for cooking and absorb sufficient quantity of water. These results are in conformity with findings of (Bansal et al., 2006).

On the basis of the above study we concluded that the seed and grain quality parameters were higher in SRI method of cultivation compared to conventional transplanting (CT) and Rice varieties also respond well for SRI method of cultivation than CT. SRI Method of cultivation is advantageous to the paddy farmers for quality seed production.

\section{References}

Abul-Baki, A.A., and Anderson, J.D. 1973. Vigour determination in soyabean seed by multiple criteria. Crop Science.13: $630-633$.

Anonymous. 1996. International rates for seed testing. Seed Science and Technology. (Supplement). 29: 1-335.

Bansal, U. K., Kaur, H and Saini, R.G. 2006. Donors for quality characteristics in aromatic rice. Oryza. 43(3):197-202.

Bhonsle, J.S., and Krishnan, S. 2010. Grain quality evaluation and organoleptic analysis of aromatic rice varieties of Goa, India. Journal of Agricultural Science. 2(3). www.researchgate.net/. 
Chapagain, T., and Yamaji, E. 2010. The effects of irrigation method, age of seedling and spacing on crop performance, productivity and water wise rice production in Japan. Paddy Water Environ. 8(1): 81-90.

Gomez, K.A., and Gomez, A.A. 1984.

Statistical procedure for Agriculture Research. $2^{\text {nd }}$ ed. John Willey and Sons, New York. 680.

Kanaka Durga, K., 2012. Influence of seedling age and spacing on productivity and quality traits of rice under System of Rice Intensification. Madras Agricultural Journal. 99 (4 -6): 301-304.

Laulanie, H., 1993. Le systeme de rigiculture intensive malagache. Tropicultura (Brussels). 11: 104-114.

Little, R.R., Hilder, G.B and Dawson, E.H. 1958. Differential effect of dilute alkali on 25 varieties of milled white rice. Cereal Chemistry. 35: 111-126.

Nandisha, B.S., and Mahadevappa, M. 1984. Influence of mother plant and nutrition and spacing in planting value of rice seeds. Seed Research. 12(2): 52-32.

Perez, C.M., and Juliano, B.O. 1978. Modification of the simplified amylose test for milled rice. Starch/ Siaerke. 30: $424-426$.
Ramaiah. 1969. Systemic classification of rice. Rice Research in India. ICAR, New Delhi.

Rita, B., and Sarawgi, A.K. (2008). Agromorphological and quality characterization of badshah bhog group from aromatic rice germplasm of Chhattisgarh. Bangladesh Journal of Agriculture Research. 33(3): 479-492.

Shukla, S., Bloese, J and Ray, T. 2016. Effect of yield, quality attributes and cost of rice (Oryza sativa L.) variety under System of Rice Intensification (SRI) organic \& conventional methods of rice cultivation. International Journal of Scientific and Research Publications. 6 (6): 313-316.

Singh, R.K., Singh, A.N., Ram, H., Rajendra Prasad, S and Chauhan, R.K. 2013. Response of basmati (Oryza sativa L.) rice varieties to System of Rice Intensification (SRI) and conventional methods of rice cultivation. Annals of Agricultural Research. 34(1): 50-56.

Uday Kumar. 2005. Studies on System of Rice Intensification (SRI) for seed yield and seed quality. M.Sc (Ag.) Thesis. Acharya N.G. Ranga Agricultural University, Hyderabad, India.

\section{How to cite this article:}

Kumar, G., L.V. Subba Rao and Keshavulu, K. 2017. Comparative Evaluation of Seed and Grain Quality Parameters of Rice (Oryza sativa L.) Varieties under SRI and Conventional Methods of Rice Cultivation. Int.J.Curr.Microbiol.App.Sci. 6(8): 3653-3660. doi: https://doi.org/10.20546/ijcmas.2017.608.442 